\title{
CREACIÓN DE UNA INFOGRAFÍA COLABORATIVA PARA PROMOVER EL CONSUMO DE FRUTA EN LA ETAPA DE INFANTIL
}

\author{
Juan Manuel Enríquez \\ elnota23@gmail.com \\ CEIP REYES CATÓLICOS DE CÁDIZ \\ Lourdes Aragón \\ lourdes.aragon@uca.es \\ UNIVERSIDAD DE CÁDIZ
}

Recibido: 16 de abril de 2018 Aceptado: 21 de mayo de 2018 DOI: http://dx.doi.org/10.15366/didacticas2018.19.005

\section{Resumen}

En el presente trabajo se expone una experiencia didáctica desarrollada en la etapa de infantil en la que se emplea la infografía como principal recurso didáctico. La propuesta se hace bajo un marco socioconstructivista del aprendizaje e integrando las aportaciones del pensamiento visual que soportan el uso de infografías. Se desarrolla en un aula de 25 niños de 4 años, quienes a través de una propuesta didáctica construyen su propia infografía de forma colaborativa incidiendo especialmente en el consumo de determinadas frutas de temporada. Al finalizar la propuesta los niños muestran un mayor interés hacia las frutas trabajadas incorporándolas en sus hábitos de vida, y promoviendo así, desde el aula una educación para la salud con una alimentación más adecuada.

Palabras clave: consumo de frutas, etapa de infantil, infografías, pensamiento visual.

\begin{abstract}
This paper presents a didactic experience developed in early childhood in which infographic technics have been applied as the main didactic resource. The proposal has been raised under a socio-constructivist learning approach. The methodology used integrating contributions from visual thinking that support the use of infographic. The case of study was a classroom of 25 children of 4 years old, who build their own infographic materials through a project. The content obtained by the experience favoring a meaningful and comprehensive learning process, focusing mainly on the habit of fruits consumption. At the end, the children show a greater interest in the fruits by incorporating them in their habits, and promoting, from the class environment, a health education with a more favorable diet.
\end{abstract}

Keywords: infographics, Early Childhood, fruits consumption, visual thinking. 


\section{1.- FUNDAMENTACIÓN TEÓRICA}

\section{1.- Infografías y pensamiento visual}

En plena sociedad del conocimiento en la que nos encontramos, cada vez es más frecuente visualizar en los distintos portales web el uso de infografías como soporte para ofrecer información de distinta naturaleza. Se trata de un recurso que originariamente se ha empleado en el ámbito periodístico, apareciendo la primera infografía en el 1806 (Valero 2001, citado en Muñoz, 2014). Debido a su gran capacidad para contar historias, explicar hechos o describir situaciones, su uso se ha extendido a otros ámbitos como es el educativo (Muñoz, 2014). De hecho, Abio (2017) señala que en el trienio 2014-2016 se ha venido observado una tendencia creciente en el número de trabajos académicos que se refieren al uso de infografías y visualización de datos que están relacionadas de algún modo con el mundo educativo. En este contexto las infografías suelen utilizarse bajo dos modalidades; como una manera en la que el docente presenta al alumnado la información de una forma más atractiva para lograr despertar su interés hacia los contenidos a trabajar, o bien, como estrategia para promover en los estudiantes otras habilidades como la búsqueda, síntesis y presentación de la información que se ponen en juego a la hora de crear los alumnos su propia infografía (Muñoz, 2014; Aragón, Jiménez-Tenorio y Vicente, 2018). Asimismo, si las infografías se elaboran en formato digital, su uso puede contribuir significativamente al desarrollo de la competencia digital (Liarte, 2014). Por su parte, Rivadeneira (2016) señala que la elaboración de infografías en el aula puede contribuir también al proceso de construcción de los aprendizajes de forma colaborativa ya que este material permite trabajar de una manera más rápida y clara las ideas principales de un tema, favoreciendo además, la memorización comprensiva de la información por parte de los alumnos.

En la bibliografía es difícil encontrar una única definición para referirnos a las infografías. Por un lado, el Observatorio Tecnológico del Ministerio de Educación, Cultura y Deporte, señala que en el caso de una infografía digital, es un método para representar la información de forma icónica y textual de manera que el usuario pueda comprenderla fácilmente empleando para ello herramientas informáticas (http://educalab.es/intef/tecnologia/observatorio-tecnologico). Abio (2017) citando a Menezes y Pereira (2016), define las infografías como soportes de información que presentan de forma combinada textos, símbolos, íconos, diagramas y dibujos entre otros elementos, los cuales son armónicamente jerarquizados y se integran de manera que permitan visualizar la información de una forma más fácil y rápida. Por su parte, Rivadeneira (2016) indica que una infografía es un documento gráfico, con imágenes y dibujos, que sirve para presentar un tema a tratar, haciendo que la información sea más atractiva y entendible para el público al que va dirigida. Otros trabajos nos acercan al concepto de infografía didáctica, refiriéndose a esta como "un conjunto de estructuras enunciativas de característica textual e iconográfica que expresan un contenido referente a un acontecimiento particular transformándolo en un saber público" (Reinhardt, 2016, 
p.41). Esta definición se aproxima más a la idea de infografía como "resultado de un proceso de pensamiento", o bien "de diseño de un espacio de sentido" y no el producto o resultado de la aplicación de determinadas herramientas y técnicas, según establece la misma autora.

En cuanto al uso de las infografías como recurso didáctico, diversos estudios evidencian un incremento del conocimiento de los estudiantes tras su utilización en el aula (Minervini, 2005; Valero 2008). Se considera que un aspecto esencial que posee la infografía es "el poder estético de captación de la atención dada su fuerte componente visual" (Valero, 2008, p.61), lo que la convierte en un recurso didáctico con un elevado potencial, además de favorecer la capacidad del alumno para visualizar procesos, ofrecer una visión del pasado, escenificar el presente e imaginar el futuro (Valero, 2008). Este potencial didáctico parece estar muy relacionado con algunas tendencias psicológicas que se apoyan en la idea de que el conocimiento es adquirido a partir de lo visual, de manera que visualizando los conceptos o bien reconociéndolos, aumenta la posibilidad de que estos puedan ser manejados (Vera, 2008). Por tanto, el uso de infografías es apoyado en gran medida por el pensamiento visual o el denominado visual thinking. Este término fue introducido por primera vez por Rudolf Arnheim en 1969, en el que se integran ciertos conceptos como la percepción, la ejecución activa de la mente, las imágenes y los símbolos o la acción selectiva del sentido de la vista. Púñez (2017) señala que según algunas investigaciones, el hombre antes de comunicarse piensa en imágenes, más que en palabras, y las vuelve a recepcionar nuevamente en imágenes. Así, el pensamiento visual puede ser considerado como otro tipo de comunicación, que de una manera más libre, didáctica, divertida y desafiante, permite activar ciertas zonas del sistema nervioso, la expresión de la razón, y las emociones sobre lo que las personas observan, y opinan, también lo que piensan, leen inventan, escuchan activamente, imaginan y comunican (Púñez, 2017).

En Púñez (2017, p.165), se incluyen además varias definiciones interesantes para comprender qué es el pensamiento visual. Según Roam (2009),

el pensamiento visual significa aprovechar la capacidad de ver tanto con los ojos como el ojo de la de la mente para poder describir las ideas que de otro modo serían invisibles, desarrollarlas rápida e intuitivamente y luego compartirlas con otras personas de una manera que ellas puedan captar de manera simple.

Para Molla (2016),

el pensamiento visual es la capacidad de capturar información, ideas, procesos y expresarlas visualmente con alto impacto; ayuda a crear en todos un sentido de totalidad, la información viaja a otros lugares y personas, crea estrategias de forma inclusiva y no exclusiva, motiva a contar una historia y dar mejores ideas, todos pueden seguir el proceso durante y después. 
Existen distintas formas para presentar el pensamiento visual; comics, mapas mentales, muros colaborativos, tomas de notas o las ya mencionadas infografías, entre otras técnicas, que combinan imágenes, símbolos o metáforas visualizadas con textos breves, lo que permiten desarrollar habilidades cognitivas, emocionales, la creatividad o el pensamiento crítico (Púñez, 2017).

Respecto a la experiencia didáctica que se desarrolla en este trabajo se integra los principios que soportan el pensamiento visual, que son puestos en juego con la elaboración de la infografía, con un marco socioconstructivista del aprendizaje. Desde esta visión se defiende la idea de que son las personas quienes seleccionan, asimilan, procesan, interpretan y confieren significaciones a los estímulos frente al hecho de que son agentes pasivos en la construcción de su aprendizaje (Coll, 1990). En este sentido, los procesos escolares son entendidos como procesos interactivos en los que intervienen tres elementos claves: el alumno que lleva a cabo un aprendizaje, el contenido objeto a aprender; y el profesor que interviene como mediador y facilitador de ese aprendizaje (Coll, 1990).

\section{2.- Promoción de la salud en la etapa de infantil: el consumo de frutas}

El programa "Creciendo en Salud" puesto en marcha por la Junta de Andalucía desde el año 2014, permite realizar un trabajo en el ámbito de la promoción y la educación para la salud en la escuela y está orientado a toda la comunidad educativa: alumnado, profesorado y grupos relevantes del entorno inmediato en relación con la salud (http://www.juntadeandalucia.es/educacion/portals/web/ced). El programa tiene como objetivo principal desarrollar los valores y las habilidades personales necesarias para sentar las bases del cuidado, mejora y mantenimiento de la salud desde los tres años de edad y a lo largo de toda la vida de cada persona. Dicho programa se dirige a las etapas de Infantil y Primaria y se configura como una herramienta que incide en la mejora de las conductas saludables del alumnado desde la práctica educativa diaria. Se pretende dotar al alumnado de esas competencias clave en la promoción de la salud. La puesta en marcha y aplicación del programa "Creciendo en Salud" supone llevar acabo al menos una de las siguientes líneas de intervención: Educación Socio-Emocional, Estilos de Vida Saludable, Autocuidados y Accidentalidad, Uso Positivo de las Tecnologías de la Información y de la Comunicación y Prevención del Consumo de Sustancias Adictivas. Cada centro que solicita el programa selecciona las líneas que quiere trabajar siendo la de Educación Socio-Emocional, la única obligatoria mientras que el resto son optativas.

Una alimentación saludable y equilibrada desde edades tempranas supone un aspecto fundamental para garantizar un crecimiento y desarrollo adecuados de los niños, así como para promocionar la salud del adulto (Vergara et al., 2016). Actualmente, existe una necesidad de estudiar la alimentación en todas las etapas educativas, fomentando especialmente, los valores positivos que se relacionan con la salud personal y de la sociedad (Del Carmen, 2010). Un estudio realizado en 2014 en tres centros educativos de España pone de manifiesto que existen ciertas deficiencias en cuanto al consumo de frutas 
y verduras en estudiantes de edades comprendidas entre 13 y 22 años. La investigación revela que estos no cumplen con los requisitos mínimos para considerar una alimentación saludable; no consumen frutas diariamente y más de la mitad de los encuestados nunca lleva fruta al colegio (Da Rosa, De Oliveira y Jiménez-Ridruejo, 2016). Por otro lado, este estudio arroja un dato interesante, y es que el $89,30 \%$ de los estudiantes que participaron en el estudio, respondieron no realizar ninguna actividad educativa en su centro relacionada con las frutas o verduras. Por otro lado, Davó et al. (2008) realizaron una investigación con objeto de conocer las características de las intervenciones destinadas a la educación y la promoción de la salud en la educación Infantil y Primaria en España a través de los estudios publicados en revistas científicas. Como resultado estos investigadores señalaron que sólo 26 de los 346 artículos identificados cumplían con los tres criterios de inclusión establecidos: 1) trabajos de salud desarrollados en España y publicados entre 1995 y 2005, 2) trabajos centrados o que incluyen las etapas de Infantil y Primaria y 3) que incorporan actividades de educación y/o promoción a la salud. Dicho estudio, indicó además, que los programas de educación llevados a cabo para la salud poseen una visión más preventiva de la enfermedad que de promoción de la salud y no parece ser frecuentes en ninguna de las etapas consideradas. Ante este resultado, Davó et al. (2008) recomiendan indagar más en las programaciones de aula para obtener una mejor información sobre las intervenciones que se realizan en los centros educativos y conocer así cómo se adecuan éstos a sus necesidades. En este sentido, un estudio realizado a nivel de centro, señala que a pesar de que las escuelas realizan actividades de promoción de la alimentación saludable, sobre todo en la etapa de Infantil, estas no parecen estar plenamente integradas en la educación formal. Según las concepciones de los maestros y enfermeros entrevistados en el estudio, los resultados indican que la responsabilidad se trasladada desde sanidad a educación, recayendo finalmente en la familia. Asimismo, la atención sanitaria a escolares en la actualidad queda reducida a revisiones físicas y vacunaciones (González, 2009).

En el CEIP Reyes Católicos de Cádiz, el programa "Creciendo en Salud" de la Junta de Andalucía se lleva desarrollando desde el curso escolar 2014/2015, concretamente se trabajan las líneas de Educación Socio-Emocional y Estilos de Vida Saludable. En nuestro caso, se decidió no solo introducir el consumo de frutas al alumnado a la hora del desayuno de media mañana, sino además se planteó introducir el componente de la variedad. El profesorado detectó una necesidad, en el sentido de que era muy habitual en nuestro alumnado que el consumo de fruta quedara restringido a unas pocas frutas, sobre todo al plátano. Con el fin de mejorar esta situación se llevó a cabo una actividad integrada a nivel de centro y con carácter mensual denominada "Fruta del mes". Dicha actividad se inició en el mes de noviembre y finalizó en mayo con la siguiente distribución (Tabla 1): 


\begin{tabular}{|c|c|c|c|c|c|c|}
\hline Noviembre & Diciembre & Enero & Febrero & Marzo & Abril & Mayo \\
\hline Mandarina & Uva & Manzana & Kiwi & Naranja & Fresas & Melocotón \\
\hline
\end{tabular}

Tabla 1. Distribución mensual de la fruta dentro del programa "Creciendo en Salud" en el centro CEIP Reyes Católicos de Cádiz.

Comer alimentos de temporada tiene múltiples beneficios; por un lado, se consumen frescos, casi recién cosechados y por el otro, son más económicos ya que abundan. Los expertos aconsejan comer frutas y verdura en su temporada natural de recolección y maduración, pues es cuando su aporte de vitaminas y sabor está a sus niveles más altos. Además se ayuda a mantener la economía local y por último, es una forma de conectar con el ciclo natural de las estaciones. Esta iniciativa se puso en marcha en el curso 2015/2016, con el objetivo de que el alumnado conozca y consuma, al menos una vez al mes, como tentempié de media mañana la fruta de temporada seleccionada. La propuesta fue discutida y aprobada en claustro para a continuación, informar a las familias de la iniciativa (objetivos, fechas...) y solicitar su colaboración e implicación, utilizando para ello tanto las redes sociales del centro como las notas informativas que se entregaron al alumnado. Quedó establecido el tercer martes de cada mes, posteriormente se cambió al segundo al coincidir con el Plan de consumo de frutas, como el día en que todo el alumnado tenía que traer y consumir la misma fruta.

\section{2.- OBJETIVOS}

Acorde a las orientaciones que propone Del Carmen (2010) sobre mejoras en la intervención educativa respecto al tema de la alimentación en los centros, la experiencia que se desarrolla a continuación, incide principalmente en el objetivo de ayudar a disfrutar de la variedad de productos, en nuestro caso de frutas de temporada, que tenemos. Ya que de acuerdo a Del Carmen (2010), algunos de los problemas que existen actualmente relacionados con la alimentación son resultado del espectro tan reducido de alimentos y formas de preparación que se acostumbra usar en muchos hogares. Por tanto, en el presente trabajo se diseña y se desarrolla una propuesta didáctica utilizando la infografía como principal recurso educativo para finalmente, difundir y compartir las producciones realizadas por el alumnado y el conocimiento generado a través del blog de aula y de youtube. Por otro lado, se pretende con nuestra propuesta, dar a conocer y fomentar el consumo de determinadas frutas de temporada en un aula de infantil. Para ello, la propuesta didáctica fue diseñada con el fin de alcanzar los siguientes objetivos didácticos:

1. Descubrir a través de los sentidos las características de las distintas frutas: melocotón, paraguayo y nectarina.

2. Promover en el alumnado el desarrollo de habilidades tales como búsqueda, síntesis y presentación de la información. 
3. Favorecer e interesar al alumnado en la importancia y los beneficios del consumo de fruta de temporada en el alumnado y que éstas sean variadas como parte de una alimentación sana y equilibrada.

4. Implicar a las familias en la promoción del consumo variado de fruta y favorecer su participación activa en la realización de la propuesta didáctica.

5. Favorecer en el alumnado procesos de observación y explora como formas de acercarse al conocimiento científico.

6. Proponer situaciones de aprendizaje cooperativo con la creación de una infografía, propiciando espacios donde el alumnado tengan que debatir, asumir diferentes roles, escuchar de forma activa y tomar decisiones.

Por otra parte, a través del uso de la infografía se pretendía dar cabida a los principios metodológicos que el programa "Creciendo en Salud" marca para la aplicación del mismo y que desde nuestro centro se han tenido en cuenta:

- Partir de las motivaciones, intereses e ideas previas del alumnado para la selección de los contenidos de cada bloque temático.

- Las actuaciones docentes que se desarrollen deben estar integradas en el currículo y en la dinámica general del trabajo en el aula desde una perspectiva transversal o interdisciplinar.

- Propiciar la innovación en el desarrollo de estrategias y métodos que faciliten la práctica docente desde una perspectiva novedosa favoreciendo tanto el trabajo colaborativo de los docentes como el intercambio de experiencias.

- Destacar los aspectos positivos, enfatizando las ventajas de los comportamientos saludables en lugar de mostrar los inconvenientes de las conductas poco saludables.

\section{3.- DESARROLLO DE LA PROPUESTA DIDÁCTICA}

\section{1.- Actividades iniciales: exploración de ideas previas}

El melocotón a pesar de ser una fruta habitual y accesible en la época del año en la que se desarrolló la propuesta didáctica (en el mes de mayo), se observó que no suele formar parte del consumo habitual de los niños de esta clase teniendo en cuenta la fruta que suelen traer para desayunar a media mañana. Asimismo, en esta primera fase de exploración de ideas previas de los niños sobre esta fruta, se comprobó que nuestro alumnado desconocía muchos aspectos sobre la misma: "¿es una fruta dura o blanda?, ¿tiene hueso o semillas?, y por dentro, ¿de qué color es?”. Estas cuestiones se abordaron llevando melocotones a clase, para que lo que los niños pudieran observarlos, tocarlos y olerlos, conociendo así algunas de sus características básicas: su textura, olor, color y dureza. 
Esta primera fase se complementó además con otras actividades (Anexo 1). En primer lugar se realizó una cata que les dejó muy buen sabor de boca y un conocimiento más completo de esta fruta. Tras conocer físicamente al melocotón era el momento de conocer la palabra. Para ello, vimos cuantas partes (silabas) tenía y qué letras conformaban la palabra "melocotón", para pasar después a colorearlas y recortarlas. Estas últimas tareas se hicieron por parejas y los colores se decidieron que fueran el rojo, el amarillo y el naranja que eran los predominantes en esta fruta. Con las letras coloreadas y recortadas era el momento de colocarlas en el panel y empezar a ver qué información podíamos obtener con cada una de esas letras y que supondrían el contenido de la infografía. La elección de la información de cada una de las letras estaba dirigida por el tutor del aula, aunque eran los niños quienes debían buscar la respuesta a las cuestiones y los retos que el docente les iba planteando. Las letras que trabajamos de la palabra MELOCOTÓN para construir nuestra infografía fueron la M, E, L, C, T, N.

\section{2.- Actividades de desarrollo: construyendo la información para elaborar la infografía}

La secuencia de trabajo con cada una de las letras para crear la infografía colaborativa fue la siguiente: "M" se trataba de buscar que "meses" eran los mejores para comer melocotones. Para esta clase se utilizó la Pizarra Digital (PDI) para relacionar las frutas del año con sus meses óptimos de consumo, estableciendo relaciones entre frutas y estaciones del año. Esta información sirvió además, para reflexionar en torno al concepto y la importancia de tomar frutas de temporada, ya que por ejemplo, por cuestiones nutricionales, la fruta de verano es muy hidratante por estar compuesta fundamentalmente por agua.

La "E" de "España"; se trataba primero de buscar que parte de España era donde había más melocotones. En el espacio de la asamblea, cinco niños colocaron pegatinas en aquellas zonas de España que creían que se producían más melocotones. Cada vez que se colocaba una pegatina en un lugar de España nos servía para comentar alguna característica de esa zona: si era un lugar de costa o de montaña, si habitualmente hacía frío o calor. Posteriormente, con todas las pegatinas situadas en el mapa todo el grupo clase votó cuál de ellas creía que era la zona de mayor producción. Comentar que ninguna de las zonas que habían sido seleccionadas correspondía con la de mayor producción de melocotón, así que tras darles una serie de pistas pudimos situar finalmente en Aragón y Cataluña como los lugares de mayor producción. Una vez que conocíamos este dato la pregunta era saber cómo estábamos en comparación con el resto del mundo, para ello, se comprobó a partir de una tabla de producción, recogida de varios portales en internet, que España es uno de los países donde se cultivaban más melocotones del mundo. Los avances de nuestras investigaciones con cada una de las letras se fueron anotando en un panel que nos serviría de esbozo para luego seleccionar las imágenes que completarían la infografía (Figura 1). 


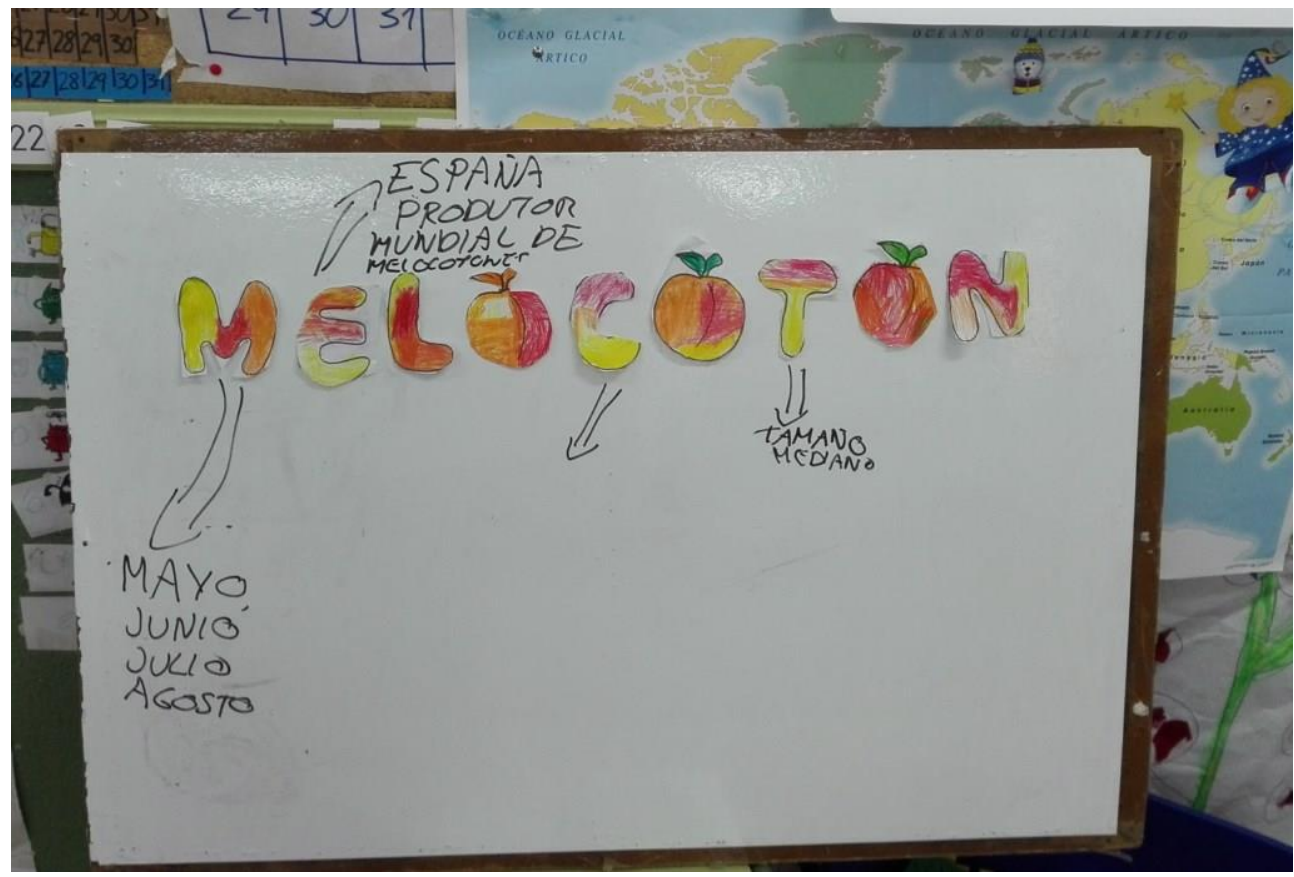

Figura 1.- Primer esbozo de la infografía elaborada por los niños de 4 años a través de la información obtenida a través de las actividades (Fuente: Elaboración propia).

Con la letra "T", se trataba de determinar el "Tamaño" del melocotón. Esta tarea la hicieron en grupos de 5 y 6 alumnos. Para ello, se le entregó a cada equipo una serie de imágenes de frutas diferentes, a excepción del melocotón que la tenían todos los grupos. Cada grupo debía pegar cada imagen atendiendo al tamaño de la fruta, de mayor a menor (Figura 2). Una vez decidido y consensuado el orden en la escala, cada equipo escribió el nombre de cada una de las frutas.

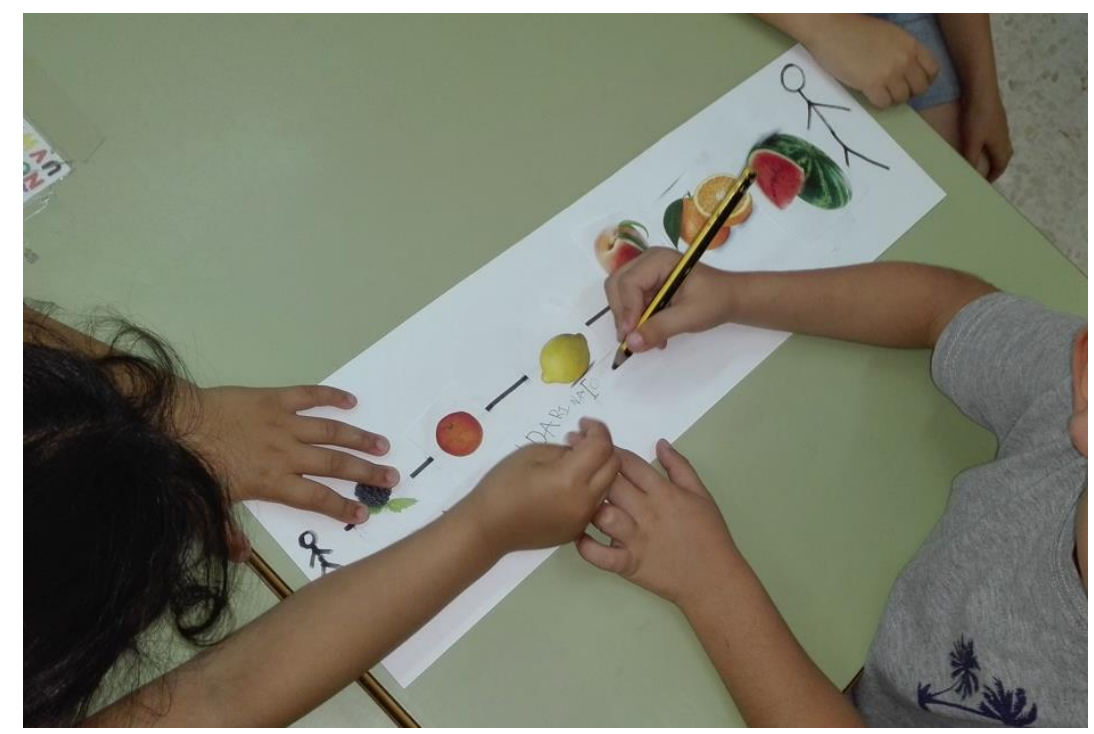

Figura 2.- Actividad en grupos pequeños para ordenar las frutas de mayor a menor tamaño (Fuente: Elaboración propia). 
Por último, tenían que presentar su trabajo en la asamblea al resto de la clase. Una vez que todos los trabajos fueron presentados, había que determinar el tamaño del melocotón, teniendo en cuenta que todos los equipos lo habían situado en la mitad de la escala, se concluyó de forma unánime que su tamaño era mediano (Figura 3).

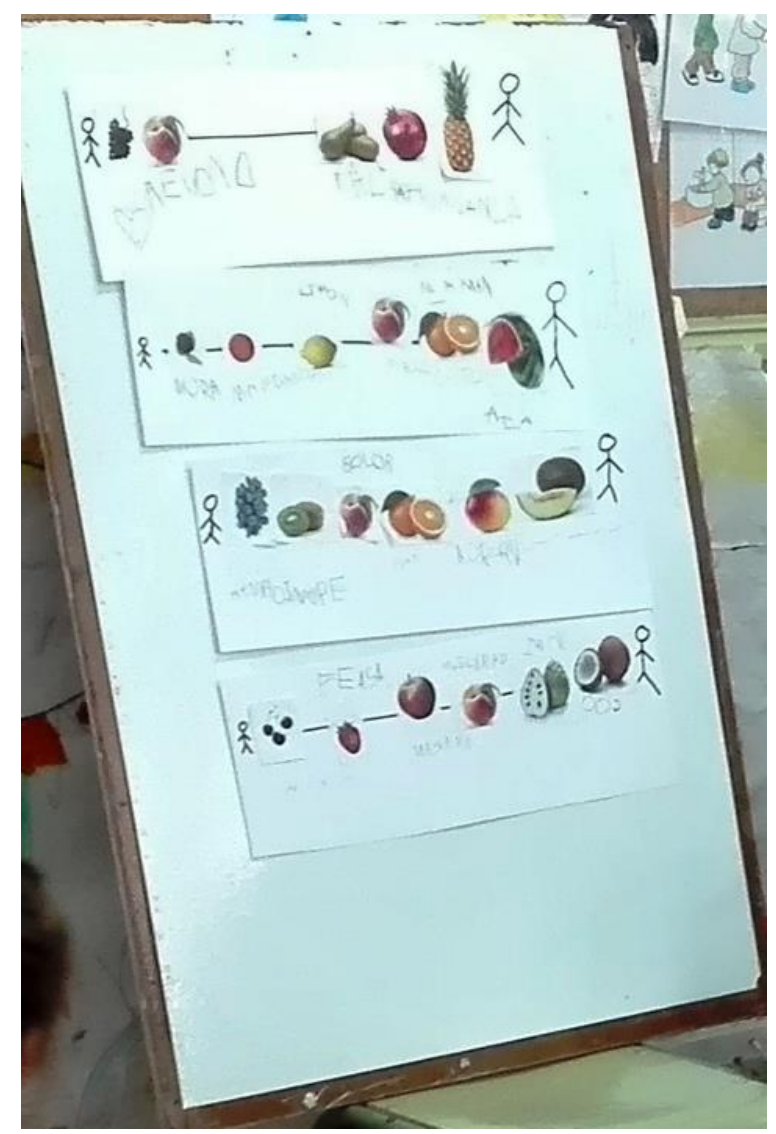

Figura 3.- Exposición del trabajo de cada uno de los grupos pequeños para determinar el tamaño del melocotón (Fuente: Elaboración propia).

La "C"; con esta letra se tenía que encontrar el país de origen del melocotón. Para ello los grupos se apoyaron en tres pistas ofrecidas por el docente. La primera era buscar países en el planisferio que empezaran por la letra C (Figura 4). Para ello, los niños en grupos de 5 iban al planisferio e iniciaban la búsqueda. El docente fue anotando en la pizarra los países que iban encontrando. Una vez que se dio por concluida la búsqueda era el momento de leerlos y volver a situarlos en el mapa. Fue un trabajo complejo que ayudó a diferenciar países, ciudades, mares y océanos. Los niños fueron comprobando, por ejemplo, que los países en el planisferio estaban escritos en letra mayúscula y que además, estaban en negrita. Con tantos países con letra $\mathrm{C}$, era el momento de dar la segunda pista; el país que buscábamos era muy grande. De esta forma la lista inicial de más de 10 países se redujo a dos países China y Canadá. 


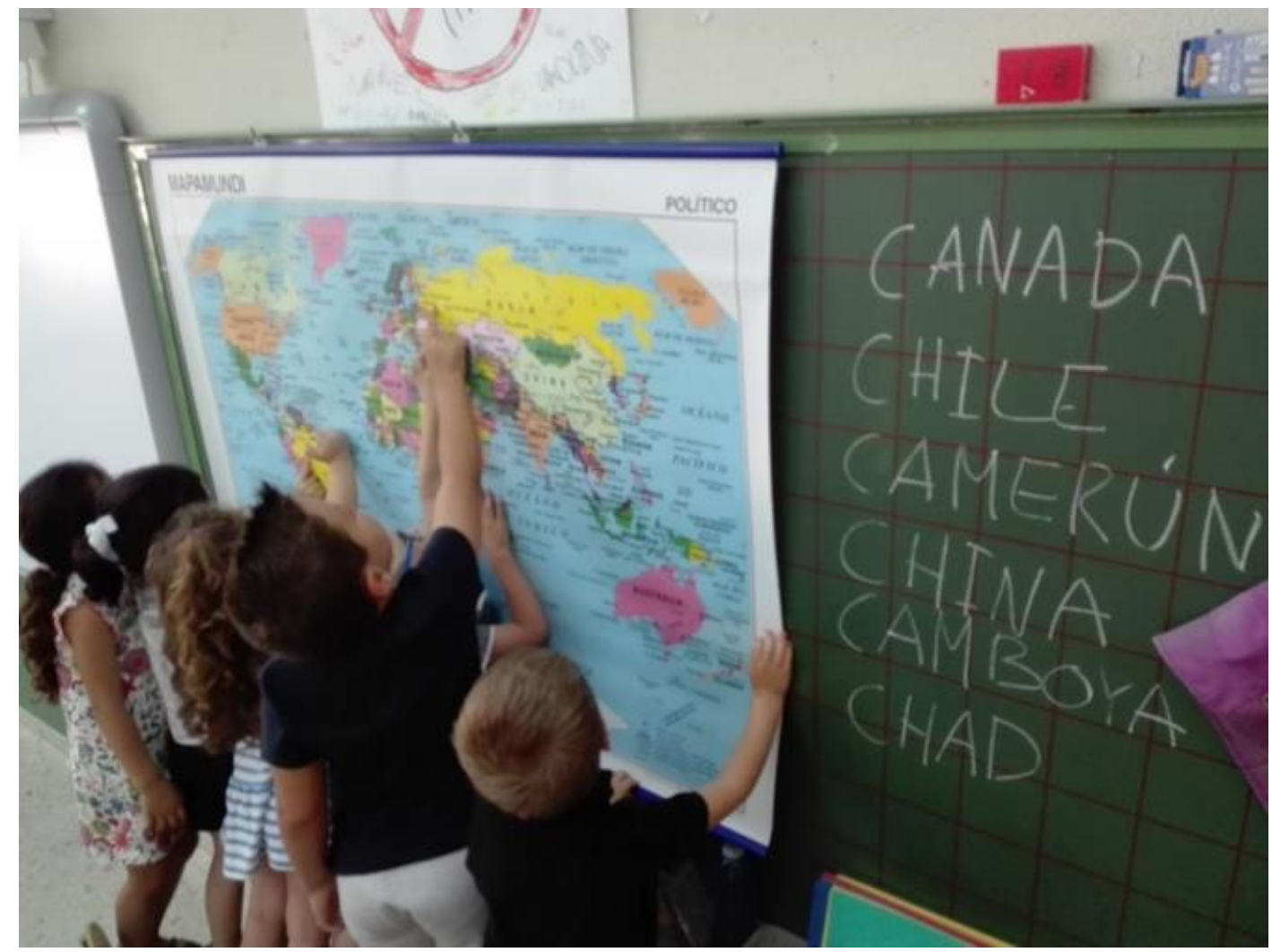

Figura 4.- Uso del planisferio para encontrar el país de origen del melocotón (Fuente: Elaboración propia).

La última pista era reconocer el idioma de este país, para eso el docente utilizó un audio que los grupos identificaron inmediatamente como chino, por lo que ya se tenía el país de origen del melocotón, China.

Finalmente, con la letra "N", se pretendía conocer otras variedades del melocotón en este caso, la nectarina y el paraguayo. Para ello, se utilizó la PDI donde cada equipo de trabajo tenía que decidir qué dos frutas eran las que buscábamos. Al ir presentado las frutas, la nectarina y el paraguayo, se observó que eran desconocidos visualmente por todos los niños, una vez nombrados, alguno sí reconoció, en el caso del paraguayo, que lo había comido. Tras dar cada uno su voto sobre quién creía que era más cercano al melocotón y hacer recuento ninguno de los posibles (paraguayo y nectarina) fue elegido. Tras la sorpresa ante quiénes eran las variedades del melocotón, había que hacerles reflexionar el porqué, y complementar la teoría con la práctica, para eso llevamos melocotones, nectarinas y paraguayos al aula para que los pudieran ver, oler, tocar y así poder observar y experimentar sus similitudes y diferencias (act. 12, ver Anexo). Los niños realizaron una observación directa y otra a ciegas con el fin de sentir y diferenciar colores, textura, tamaño, formas, entre otras cualidades presentes en las frutas. Finalmente se hizo una degustación de las tres frutas con el fin de que pudieran apreciar las diferencias de sabor y sobre todo de introducir en algunos casos, y consolidar en otros, el consumo de las mismas (Figura 5a y 5b). 


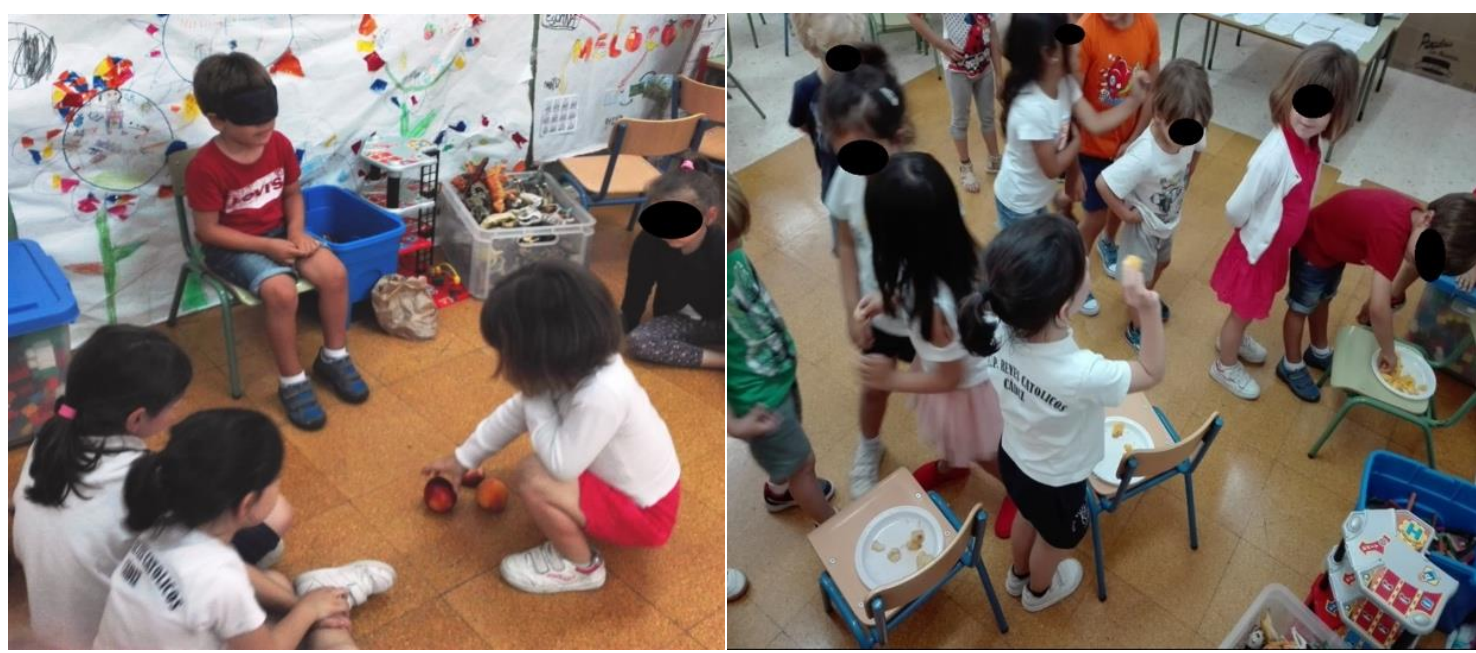

Figura 5.- De izq. a der. 5a y 5b. (a) Cata a ciegas y (b) Observación directa de las tres frutas (Fuente: Elaboración propia).

\section{3.- Actividades finales: creación de la infografía colaborativa}

Con casi todas las letras de la infografía dotadas de contenido era el momento de pasar del primer esbozo a la infografía final. Se trataba de que los dibujos no fueran excesivamente complejos y que ayudaran a verbalizar la idea clave de cada letra, pero donde la imagen tuviera un lugar protagonista y permitiera casi de forma intuitiva entender el mensaje que se quería transmitir con cada letra haciendo uso del potencial didáctico que poseen las infografías. El resultado final es el que se muestra en la Figura 6 , solo faltaba anotar la palabra clave en cada una de las letras.

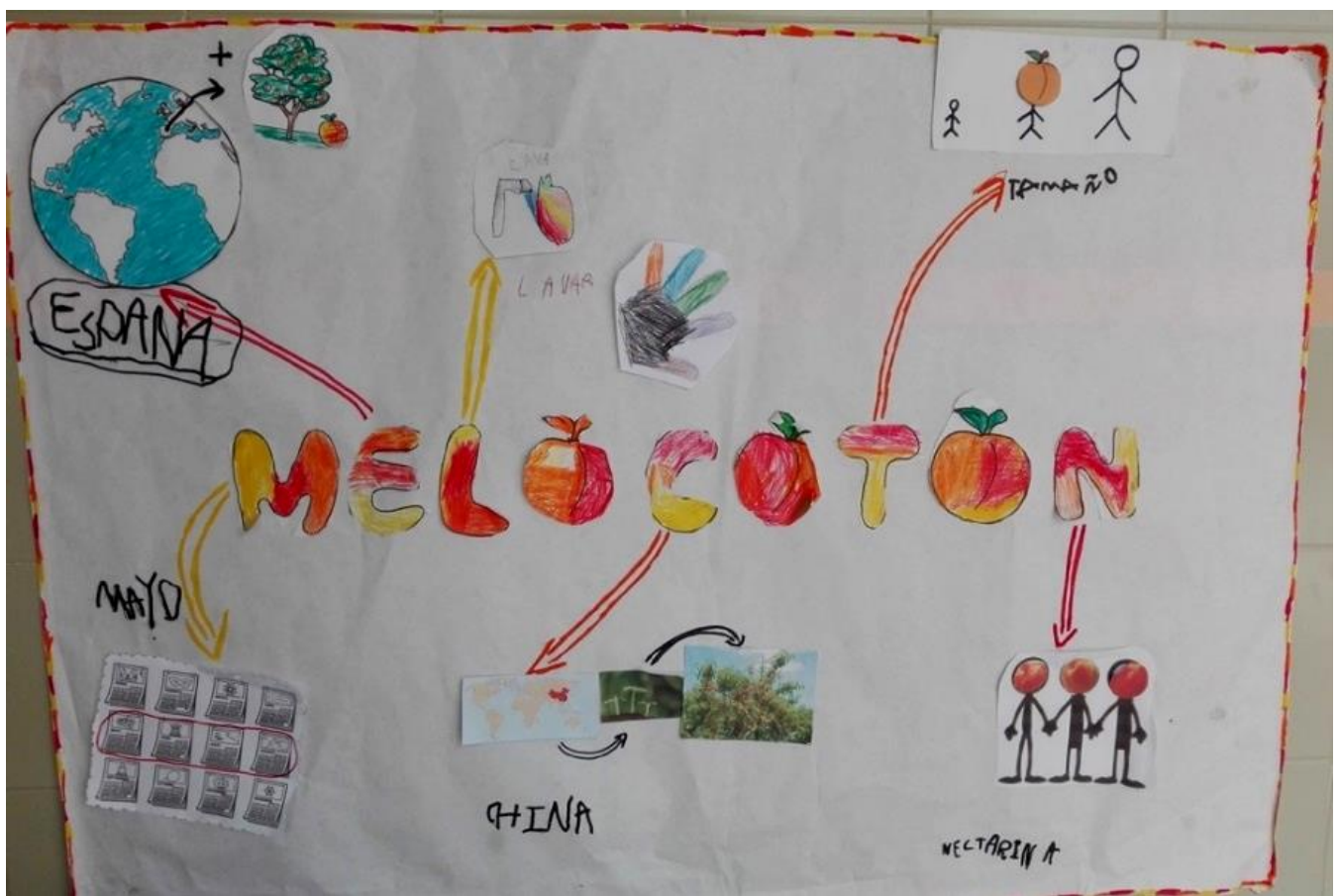

Figura 6.- Infografía final elaborada por la clase de 4 años (Fuente: Elaboración propia). 
Para terminar la infografía faltaba completar una sola letra, la "L". Para dotarle de contenido se utilizó el blog de aula (www.entre2y6.blogpost.com.es) para lanzar el reto de que buscaran, con ayuda de las familias, una palabra relevante que empezara con la letra "L" y referida al melocotón. La actividad fue todo un éxito dado que todas las familias aportaron información al respecto para completar la infografía. A continuación, cada niño presentó al resto de compañeros su propuesta sobre la letra "L" que habían elaborado en casa con las familias (figura 7a). Una vez que todas habían sido defendidas oralmente y expuestas en el corcho de la clase (figura 7b), se pasó a elegir por votación cuál sería la que incluiríamos en la infografía colaborativa. La elección fue la de "Lavar tanto el melocotón como las manos antes de comerlo”.

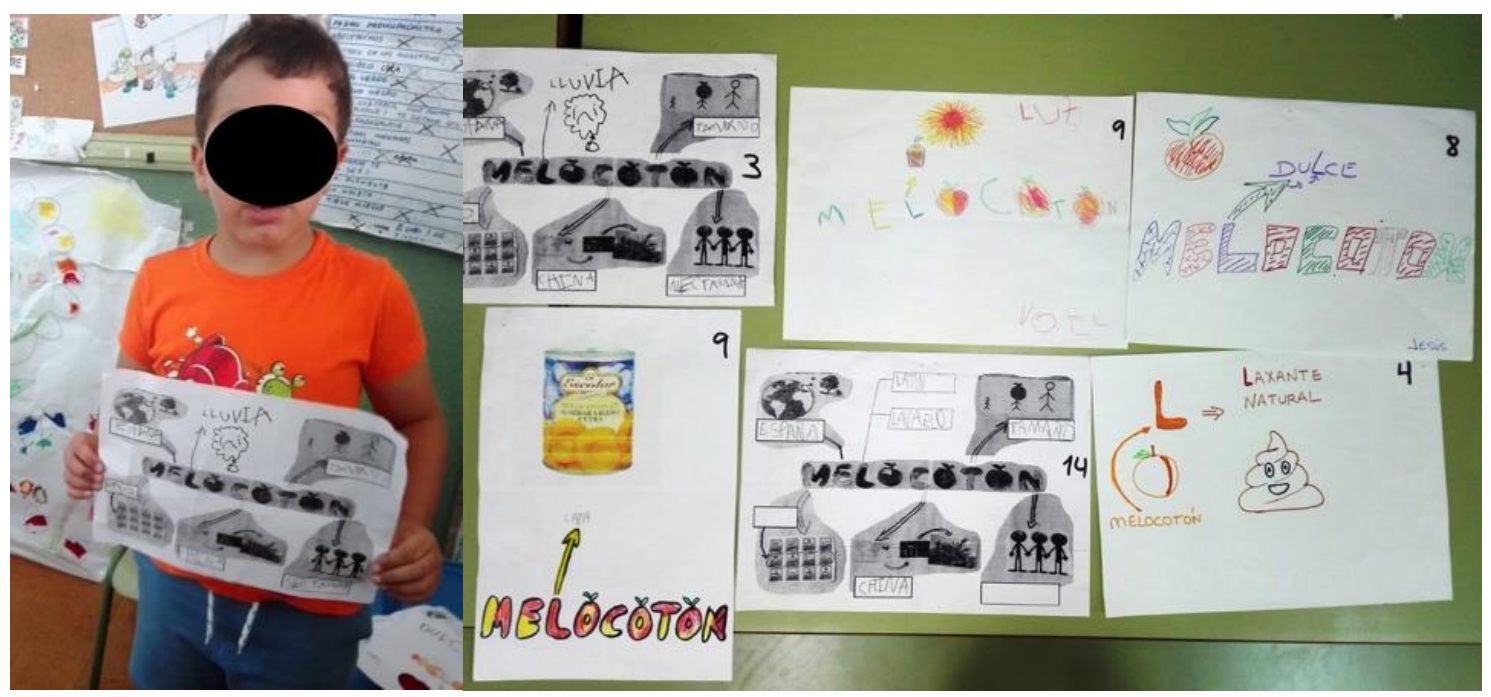

Figura 7.- De izq. a der. 7a y 7b. (a) Comunicación de la información buscada de la letra "L" de los niños con ayuda de sus familias y, (b) Proceso de exposición y votación para elegir la información que se incorpora a la infografía colaborativa.

(Fuente: Elaboración propia).

Para finalizar la propuesta y que nuestro trabajo realizado en torno al melocotón lo pudieran utilizar otros niños, compartiendo y dándole así difusión, se subió la infografía elaborada a youtube (https://youtu.be/HIgIuIGLMnk). Para ello, se aprovecharon las imágenes de nuestra infografía a la que solo quedaba añadirle los audios que fueron grabados con una App del móvil del docente, y donde los niños explicaban brevemente en qué consistía cada una de las letras.

Con el objetivo de conocer en qué medida habían asimilado la información de cada una de las letras y cómo concretar y sintetizar dicho trabajo se propuso como actividad final que cada alumno se llevara una infografía a casa en formato A4, donde tras haber escrito cada una de las palabras clave de cada letra de la misma, tenía como trabajo individual comentarla y explicarla a su familia (Figura 8). 


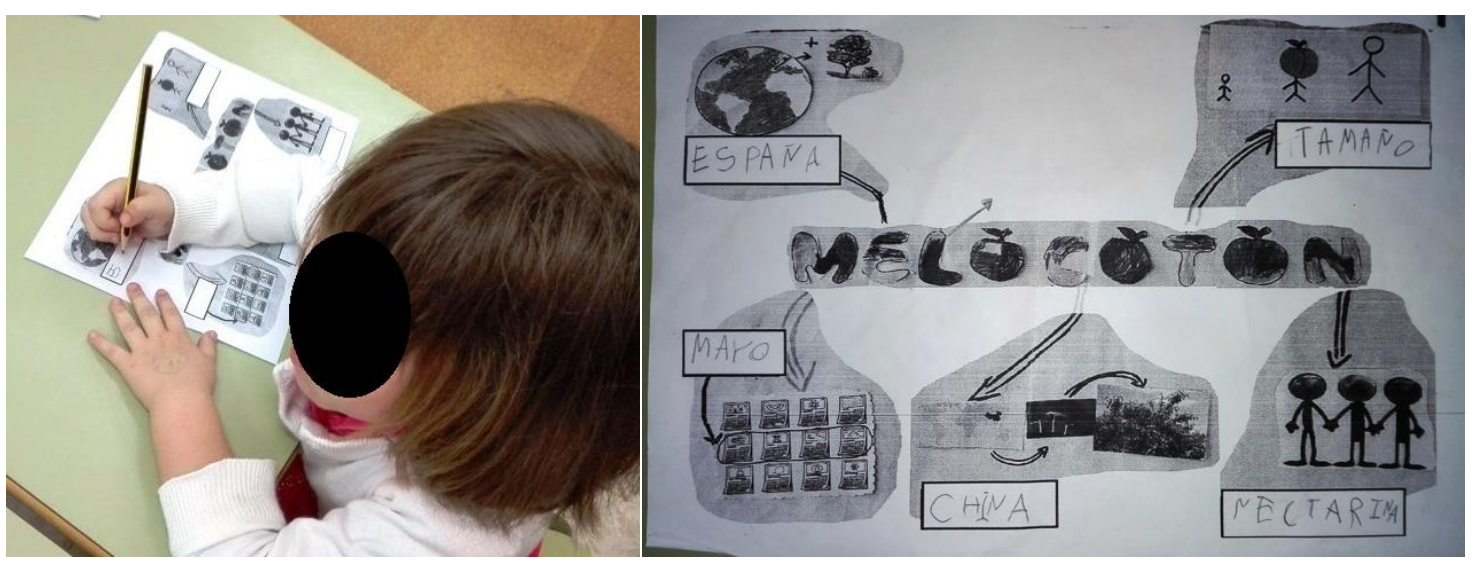

Figura 8.- De izq. a der. 8a y 8b. (a) Elaboración de una infografía para la casa como trabajo individual, b) Infografía realizada en clase y completada con el trabajo para casa de la letra "L" (Fuente: Elaboración propia).

\section{4.- EVALUACIÓN DE LA EXPERIENCIA Y PROPUESTAS DE MEJORA}

Nuestra experiencia fue evaluada durante tres momentos de la secuencia didáctica diseñada: al inicio, durante y final. La evaluación inicial se llevó a cabo recogiendo las ideas mantenidas por los niños en la asamblea sobre el melocotón y sus características, que fueron anotadas en el diario del profesor. Esta evaluación inicial fue fundamental de cara a plantear el diseño y desarrollo de la propuesta didáctica, dado que el conocimiento que mantenían los niños sobre esta fruta al inicio de la secuencia era muy escaso. Si bien, de los 25 niños participantes en la experiencia, el 88\% ( $n=22)$, no fue capaz de ofrecer información sobre las características reales del melocotón. El 100\% de los niños conocía que se trataba de una fruta, sin embargo, no era capaz de describirla con fiabilidad.

En cuanto a la evaluación procesual, esta se llevó a cabo en base a la observación sistemática del tutor realizada durante el desarrollo de algunas de las actividades para cada una de las letras que conformaban la infografía. Para evaluar la progresión y construcción de nuevos aprendizajes el docente utilizó una escala de observación en base a una serie de ítems que recogían aspectos relativos principalmente, a los procedimientos y las actitudes mostradas por el alumnado acorde a los objetivos didácticos que se pretendían alcanzar con la acción didáctica (tabla 2).

Respecto al objetivo "Descubrir a través de los sentidos las características de las distintas frutas: melocotón, paraguayo y nectarina" y en base a los ítems 1 y 2 hay que indicar que el 100\% del alumnado consiguió establecer al menos una característica diferencial de cada fruta con respecto a las demás (tamaño, forma, textura). Mientras que solo el $88 \%$ fue capaz de establecer dos o más características diferenciales entre las tres frutas trabajadas. Asimismo, con respecto al segundo ítem, hay que señalar que el $96 \%$ del alumnado probó las tres frutas, sin embargo no todos diferenciaron los sabores, y el $82 \%$ del alumnado sí apreció diferencias en el sabor y en la textura de la nectarina, el paraguayo y el melocotón. Entre el melocotón y el paraguayo los resultados mostraron que había bastante confusión y gran parte del alumnado no sabía que contestar. 


\begin{tabular}{|c|l|}
\hline \multicolumn{1}{|c|}{ Ítems } & \multicolumn{1}{c|}{ Objetivos didácticos } \\
\hline $\begin{array}{l}\text { 1- Reconoce y diferencia las características } \\
\text { físicas del melocotón, paraguayo y nectarina } \\
\text { (tamaño, forma, textura, color) }\end{array}$ & $\begin{array}{l}\text { Descubrir a través de los sentidos las características de } \\
\text { las distintas frutas: melocotón, paraguayo y nectarina. }\end{array}$ \\
\hline $\begin{array}{l}\text { 2-Prueba y diferencia el sabor de las } \\
\text { diferentes frutas trabajadas }\end{array}$ & $\begin{array}{l}\text { Descubrir a través de los sentidos las características de } \\
\text { las distintas frutas: melocotón, paraguayo y nectarina }\end{array}$ \\
\hline $\begin{array}{l}\text { 3-Participa activamente dentro del trabajo en } \\
\text { equipo, asumiendo diferentes roles y } \\
\text { respetando los de los demás }\end{array}$ & $\begin{array}{l}\text { Proponer situaciones de aprendizaje cooperativo con la } \\
\text { creación de una infografía, propiciando espacios donde el } \\
\text { alumnado tengan que debatir, asumir diferentes roles, } \\
\text { escuchar de forma activa y tomar decisiones. }\end{array}$ \\
\hline $\begin{array}{l}\text { 4-Expone su punto de vista y acepta el punto } \\
\text { de vista de los demás desde el diálogo y el } \\
\text { respeto las opiniones de los otros. }\end{array}$ & $\begin{array}{l}\text { Proponer situaciones de aprendizaje cooperativo con la } \\
\text { creación de una infografía, propiciando espacios donde el } \\
\text { alumnado tengan que debatir, asumir diferentes roles, } \\
\text { escuchar de forma activa y tomar decisiones. }\end{array}$ \\
\hline $\begin{array}{l}\text { 5-Conoce algunos beneficios del consumo de } \\
\text { fruta de temporada }\end{array}$ & $\begin{array}{l}\text { Favorecer e interesar al alumnado en la importancia y los } \\
\text { beneficios del consumo de fruta de temporada en el } \\
\text { alumnado y que éstas sean variadas como parte de una } \\
\text { alimentación sana y equilibrada. }\end{array}$ \\
\hline desayuno escolar
\end{tabular}

Tabla 2. Ítems establecidos en la escala de observación en base a algunos de los objetivos didácticos propuestos para realizar la evaluación procesual (Fuente: Elaboración propia)

Respecto al objetivo "Descubrir a través de los sentidos las características de las distintas frutas: melocotón, paraguayo y nectarina" y en base a los ítems 1 y 2 hay que indicar que el $100 \%$ del alumnado consiguió establecer al menos una característica diferencial de cada fruta con respecto a las demás (tamaño, forma, textura). Mientras que solo el $88 \%$ fue capaz de establecer dos o más características diferenciales entre las tres frutas trabajadas. Asimismo, con respecto al segundo ítem, hay que señalar que el $96 \%$ del alumnado probó las tres frutas, sin embargo no todos diferenciaron los sabores, y el $82 \%$ del alumnado sí apreció diferencias en el sabor y en la textura de la nectarina, el paraguayo y el melocotón. Entre el melocotón y el paraguayo los resultados mostraron que había bastante confusión y gran parte del alumnado no sabía que contestar.

En cuanto al objetivo "Proponer situaciones de aprendizaje cooperativo con la creación de una infografía, propiciando espacios donde el alumnado tengan que debatir, asumir diferentes roles, escuchar de forma activa y tomar decisiones", se emplearon los ítems 3 y 4, en líneas generales, el alumnado se mostró muy participativo en las tareas desarrolladas en pequeño grupo y tan solo, un $16 \%(\mathrm{n}=4)$, mostró una actitud pasiva y poco participativa ante las tareas presentadas. El $12 \%$ tuvo algunas dificultades a la hora de asumir distintos roles dentro del equipo, fundamentalmente por no asumir un papel de liderazgo. En base al análisis del ítem 4, los resultados muestran que en las dinámicas de 
clase, la toma de decisiones se realizaba bajo las premisas de diálogo y solo un $8 \%$ del alumnado no aceptaba de forma adecuada, mostrando cierto enfado, los puntos de vista y los planteamientos de los compañeros.

Finalmente, el objetivo "Favorecer e interesar al alumnado en la importancia y los beneficios del consumo de fruta de temporada en el alumnado y que éstas sean variadas como parte de una alimentación sana y equilibrada", se valoró a través de los ítems 5 y 6. En el caso concreto del ítem 5, señalar que se trata de un ítem que se repite con cada fruta del mes que vamos trabajando a lo largo del curso y en el marco del programa "Creciendo en Salud", por lo que el 100\% del alumnado conoce al menos, una ventaja del consumo de fruta de temporada.

Para la evaluación final de la propuesta, el docente recogió las respuestas ofrecidas por el alumnado durante algunas de las asambleas en las que se desarrollaban las actividades finales. En concreto en la actividad 14 (anexo 1), se utilizó la asamblea como espacio para concretar los mensajes y las frases que acompañarían a cada una de las imágenes que posteriormente se grabarían como audio para acompañar a la infografía. Se trataba de buscar una o dos frases que acompañaran a la imagen de cada una de las letras de nuestra infografía. En base a las aportaciones dadas por cada alumno se construía el mensaje de cada letra. Esto se hacía de forma consensuada y también realizando votaciones en aquellos casos donde surgían opiniones encontradas, y todo ello bajo el respeto al turno de palabra y a las opiniones de los demás. Según las ideas recogidas, las principales dificultades detectadas fueron con respecto a la letra " $E$ ", ya que en algunos casos, el alumnado consideraba España como el país donde se comen mas melocotones, y no como uno de los mayores productores. Además, con la letra "M", existían dudas con respecto a los meses de mejor consumo del melocotón, dado a ser contenidos más abstractos. Por otra parte destacar que hubo un $100 \%$ de consenso a la hora de determinar los contenidos de la letra "T" (tamaño del melocotón) y de la letra "C" (China como país de origen del melocotón), probablemente por el tipo de metodología empleada en las actividades; en el caso de la letra " $T$ " fue colaborativa y manipulativa, y en el caso de la letra "C" fue planteada a través de retos.

Asimismo, otra de las actividades utilizadas para evaluar los conocimientos de los niños fue la ficha individual realizada al finalizar la secuencia (actividad 15). Una vez completada la ficha esta era presentada al docente como paso previo a la exposición que harían en sus casas. Esa exposición ayudó a confirmar que todos los niños habían incorporado y asimilado nueva información. Por otro lado, también sirvió para detectar las dificultades que habían surgido en la elección de los audios, siendo las letras "E" y "M" las que originaban mayor confusión, si bien en porcentajes algo menores con respecto a los audios. Así, el 72\% del alumnado fue capaz de explicar de forma satisfactoria cada uno de los elementos de la infografía. Un 16\%, mostró dificultad en un elemento de la infografía, y el $12 \%$ tenía dificultades con dos o más elementos de la infografía. 
En relación al objetivo didáctico "implicar a las familias en la promoción del consumo variado de fruta y favorecer su participación activa en la realización de la propuesta didáctica", este fue alcanzado con éxito dado que el 100\% de las familias colaboró en la realización de la infografía con el trabajo de la letra "L", aportando diversos mensajes del tipo "Dulce", "Laxante natural" o "Luz para que crezca el melocotonero".

Finalmente, como se mencionó al inicio del trabajo, nuestra propuesta didáctica surgió entre otros aspectos, por la escasa variedad de frutas que traían los niños al aula para el momento del desayuno el día establecido por el centro. Aprovechando el mes en el que se diseñaba la propuesta, se decidió introducir una nueva fruta de temporada, como fue el melocotón y sus variedades. Tras el desarrollo de la propuesta, y durante los días que restaban del mes de mayo y junio para traer fruta al aula, se llevó a cabo, con la ayuda de las familias, un registro de los hábitos de consumo de esta fruta. Así, se constató que de los 25 niños, 10 de ellos ya consumían en sus casas melocotón, sin embargo, 6 más, comenzaron a hacerlo tras realizar la propuesta didáctica. Respecto al aula, se observó que durante media mañana, hubo un incremento en el número de niños que incluían en sus desayunos algunas de las frutas trabajadas. Asimismo, las familias cumplían con el plan establecido en el programa "Creciendo en Salud", el tercer martes de los dos meses restantes de curso, los niños traían a clase melocotón.

\section{5.- CONCLUSIONES Y PROPUESTAS DE MEJORAS}

Tras el desarrollo de la experiencia podemos extraer las siguientes conclusiones. En primer lugar, la valoración general que hacemos de las cuatro semanas que duró la propuesta didáctica es de muy positiva ya que se ha conseguido que el alumnado se mantenga activo e implicado en las diferentes actividades. Los niños han analizado, debatido y trabajado en equipo, aún con las limitaciones que la edad puede suponer en la realización de estas acciones, pero con el deseo de iniciarles en metodologías y actividades que permiten enriquecer y contrastar sus opiniones y diferentes puntos de vista dentro de un marco de debate y diálogo. Los niños han accedido a través de la observación y la experimentación directa a conocer y establecer las características de las frutas trabajadas.

En segundo lugar, la utilización del pensamiento visual, con el uso de la infografía, nos ha permitido conectar con una forma de conocimiento y acceso a la información que en estas edades y en esta sociedad es preeminente como es el uso de la imagen. Unas imágenes en forma de dibujos y fotografías que además de conectar con los intereses de los niños, posibilita su conocimiento de la realidad y permite difundir y compartir el conocimiento elaborado. Los niños se han iniciado en el uso del blog de aula y de plataformas de youtube como medios de conocer y compartir nuestras producciones. Pero sobre todo, y teniendo en cuenta el marco en el que se inserta la presente propuesta didáctica, como es el programa "Creciendo en Salud", y contando con la ayuda imprescindible e inestimable de sus familias, estamos consiguiendo que la alimentación 
de nuestro alumnado avance hacia unos estándares más saludables basada en el incremento del consumo de fruta, que ésta sea variada y de temporada.

Finalmente, y en base a los resultados obtenidos tras la propuesta didáctica, consideramos que no hace sino reforzar nuestro compromiso en la importancia de seguir insistiendo como centro educativo en la promoción de la salud como elemento esencial en la formación de nuestros alumnos, ya que constituye un pilar básico para su crecimiento y desarrollo armónico e integral. El profesorado implicado consideramos un aspecto fundamental, dar cabida como núcleos de aprendizaje a elementos y contenidos esenciales para la vida y el futuro de nuestro alumnado y hacerlo apostando por metodologías de base socioconstructivista, una mayor presencia de las TIC's y una mejor colaboración familia-escuela.

En cuanto a las propuestas de mejora de la intervención llevada a cabo, creemos que estas pueden ser diversas; por un lado, el alumnado debe tener aún más, un mayor protagonismo en el diseño y elaboración de las imágenes de la infografía. Asimismo consideramos que sería necesario potenciar nuevas formas de agrupamiento ya que aunque los empleados en el aula (gran grupo, grupo pequeño e individual), han funcionado bastante bien, sin embargo, el trabajo por parejas ha quedado casi ausente y se trata de una excelente forma de trabajo que no podemos obviar en próximas acciones didácticas. De cara a reforzar el conocimiento científico, sería interesante incluir actividades que permitan exponer mucho más los procesos de observación y experimentación y se hagan referencias a estos procedimientos científicos de una manera más explícita en el aula por ejemplo, elaborando tablas de doble entrada que nos permitan afianzar y visualizar, y no solo verbalizar, el conocimiento de las frutas con otras variables como el peso, tamaño, tipo de piel o tipo de hueso.

Otro aspecto interesante de cara a reforzar la importancia del consumo de frutas de temporada desde el aula, sería la visita a un mercado local. Así, se daría cabida tanto a profesiones como a los lugares de distribución de frutas. Por ello, sería interesante planificar una salida al mercado del barrio para poder comprar nosotros mismos la fruta, conocer un poco mejor nuestro entorno cercano y la comunidad de personas que allí viven y trabajan. Asimismo, sería muy enriquecedor para el alumnado invitar a agricultores ecológicos o personas relacionadas con el cultivo y/o venta de esta fruta para que nos aporten su experiencia y puntos de vista de forma que nos sirva para integrar otros tipos de saberes, y conectar la propuesta con el conocimiento cotidiano acorde a los objetivos planteados. Habría que valorar la posibilidad de hacer una salida a un huerto o campo de cultivo de estas frutas para poder conocerlas desde su producción y origen, y a ser posible saborearlas in situ. 


\section{BIBLIOGRAFÍA}

ARAGÓN, L., JIMÉNEZ-TENORIO, N., Y VICENTE, J.J. (2018). Valoraciones de los futuros maestros/as de infantil en el uso de técnicas basadas en el pensamiento visual para mejorar los procesos de enseñanza-aprendizaje en didáctica de las ciencias experimentales. En REDINE (Ed.). (2018). Conference Proceedings EDUNOVATIC 2017. Eindhoven, NL: Adaya Press.

ABIO, G. (2017). Estrategias para la indagación continuada de trabajos académicos utilizando herramientas de Google. El caso de una investigación sobre infografías en la educación. Revista de Educación Mediática y TIC, 6(2), 209-231. doi: https://doi.org/10.21071/edmetic.v6i2.6934

ARNHEIM, R. (1969). El pensamiento Visual. Barcelona: Ediciones Paidós.

COLL, C. (1990). Aprendizaje escolar y construcción del conocimiento. Barcelona: Ediciones Paidós.

DA ROSA PIASETZKI, C.T., DE OLIVEIRA, E.T., Y JIMÉNEZ-RIDRUEJO, G. (2016). Consumo de frutas e verduras de estudantes de educação básica. Revista de Didácticas Específicas, 15, 140-156. Recuperado de https://revistas.uam.es/didacticasespecificas/article/view/6906/7216

DAVÓ, M.C., GIL-GONZÁLEZ, D., VIVES-CASES, C., ÁLVAREZ-DARDET, C., Y LA PARRA, D. (2008). Las investigaciones sobre promoción y educación para la salud en las etapas de infantil y primaria de la escuela española. Una revisión de los estudios publicados entre 1995 y 2005. Gaceta Sanitaria, 22(1), 58-64.

DEL CARMEN, M.L. (2010). La alimentación: algo más que ingerir alimentos. Alambique, Didáctica de las Ciencias Experimentales, 66, 66-72.

GONZÁLEZ, A. (2009). Concepciones y practica reflexionada de docentes y enfermerasos sobre la promoción de la alimentación saludable en la escuela. Investigación en la Escuela, 69, 87-98.

LIARTE, R. (2014). Infografías. En Fernando Trujillo (coord.), Artefactos digitales. Una escuela digital para la educación de hoy. (pp.66-70). Barcelona: Graó.

MINERVINI, M.A. (2005). La infografía como recurso didáctico. Revista Latina de Comunicación Social, 8(59). Recuperado de: http://www.ull.es/publicaciones/latina/200506minervini.pdf

MUÑOZ, E. (2014). Uso didáctico de las infografías. Espiral Cuadernos del Profesorado, 7(14), 37-43. Recuperado de: http://www.cepcuevasolula.es/espiral.

PÚÑEZ, N. (2017). El Pensamiento visual: una propuesta didáctica para pensar y crear. Horizonte de la Ciencias, 7(12), 161-177. doi: http://dx.doi.org/10.26490/uncp.horizonteciencia.2017.12.319

REINHARDT, N. (2010). Infografía Didáctica: producción interdisciplinaria de infografías didácticas para la diversidad cultural. Cuadernos del Centro de Estudios 
en Diseño y Comunicación. Ensayos, (31), 119-191. Recuperado de http://www.scielo.org.ar/scielo.php?script=sci_arttext\&pid=S1853352320100001000 $03 \& \operatorname{lng}=\mathrm{es} \& \operatorname{lng}=\mathrm{es}$.

RIVADENEIRA, E.P. (2016). Infografía como recurso didáctico en el proceso de enseñanza aprendizaje del bloque 2 de ciencias naturales del octavo año de educación general básica en la unidad educativa de Gran Bretaña. Tesis doctoral, Universidad Central del Ecuador.

VALERO, J.L. (2009). La transmisión de conocimiento a través de la infografía digital. Ámbitos, 18, 51-63. Recuerado de: http://www.redalyc.org/articulo.oa?id=16812722004

VERA, E. (1998). El poder de la Imagen en el aprendizaje de segundas lenguas. Folios: Revista de la Facultad de Artes y Humanidades, 8, 65-69. Recuperado de: http://revistas.pedagogica.edu.co/index.php/RF/article/view/5777/4782.doi:http://dx. doi.org/10.17227/01234870.8folios65.69.

VERGARA, D., RÍOS-REINA, R., ÚBEDA, C., ESCUDERO-GUILETE, M.L., Y, CALLEJÓN, M.R. (2016). Menús ofertados en centros de educación infantil de Sevilla: adecuación a criterios nutricionales y a las recomendaciones dietéticas. Nutrición Hospitalaria, 33, 671-677. doi: http://dx.doi.org/10.20960/nh.277 
Anexo I. Secuencia de actividades para desarrollar la infografía colaborativa (los objetivos didácticos que se presentan en la columna 3 son los explicitados en la tabla 2)

\begin{tabular}{|c|c|c|c|c|}
\hline & Actividad & $\begin{array}{l}\text { Objetivos } \\
\text { didácticos }\end{array}$ & Agrupamiento & $\begin{array}{c}\text { Principales } \\
\text { instrumento de } \\
\text { evaluación usados }\end{array}$ \\
\hline \multirow{5}{*}{ 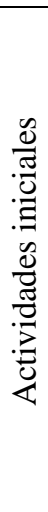 } & $\begin{array}{l}\text { Act. 1. Asamblea: } \\
\text { Exploración de ideas } \\
\text { previas }\end{array}$ & $\begin{array}{l}\text { Conocer qué } \\
\text { saben los niños } \\
\text { del melocotón y } \\
\text { sus características }\end{array}$ & Grupo clase & $\begin{array}{l}\text { Diario del profesor: } \\
\text { Recogida de ideas } \\
\text { previas en la asamblea }\end{array}$ \\
\hline & $\begin{array}{l}\text { Act. 2. Conocemos el } \\
\text { melocotón. }\end{array}$ & $1,5,6$ & Grupo pequeño & \\
\hline & Act. 3. Cata del melocotón & $1,5,6$ & Grupo clase & \\
\hline & $\begin{array}{l}\text { Act. 4. Conocemos la } \\
\text { palabra "melocotón" }\end{array}$ & 2,6 & Parejas & \\
\hline & $\begin{array}{l}\text { Act. 5. Iniciamos la } \\
\text { Infografía }\end{array}$ & 2,6 & Grupo clase & \\
\hline \multirow{8}{*}{ 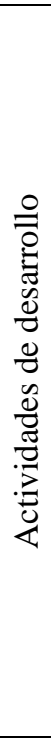 } & Act. 6. La "M" & $2,3,6$ & Grupo clase & $\begin{array}{l}\text { Observación sistemática } \\
\text { del docente }\end{array}$ \\
\hline & Act. 7. La "E" & 2,6 & Grupo clase & $\begin{array}{l}\text { Observación sistemática } \\
\text { del docente }\end{array}$ \\
\hline & Act. 8. La "T" & $2,5,6$ & $\begin{array}{l}\text { Grupo pequeño/ } \\
\text { Grupo clase }\end{array}$ & $\begin{array}{l}\text { Observación sistemática } \\
\text { del docente }\end{array}$ \\
\hline & Act. 9. Exposición grupal & $2,5,6$ & Grupo clase & $\begin{array}{l}\text { Observación sistemática } \\
\text { del docente }\end{array}$ \\
\hline & Act. 10. La "C" & $2,5,6$ & $\begin{array}{l}\text { Grupo pequeño/ } \\
\text { Grupo clase }\end{array}$ & $\begin{array}{l}\text { Observación sistemática } \\
\text { del docente }\end{array}$ \\
\hline & $\begin{array}{l}\text { Act. 11. La "N". } \\
\text { Presentación de las distintas } \\
\text { variedades del melocotón en } \\
\text { la PDI }\end{array}$ & $1,3,5,6$ & $\begin{array}{l}\text { Grupo clase/ } \\
\text { Grupo pequeño }\end{array}$ & $\begin{array}{l}\text { Observación sistemática } \\
\text { del docente }\end{array}$ \\
\hline & $\begin{array}{l}\text { Act.12. Manipulación "a } \\
\text { ciegas" de las frutas }\end{array}$ & $1,3,5,6$ & Individual & $\begin{array}{l}\text { Observación sistemática } \\
\text { del docente }\end{array}$ \\
\hline & $\begin{array}{l}\text { Act. 13. Degustación de las } \\
\text { frutas }\end{array}$ & $1,3,5,6$ & Individual & $\begin{array}{l}\text { Observación sistemática } \\
\text { del docente }\end{array}$ \\
\hline \multirow{5}{*}{ 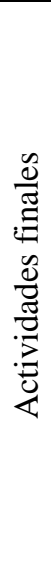 } & $\begin{array}{l}\text { Act. 14. Definir el } \\
\text { contenido de los audios de } \\
\text { cada letra trabajada hasta el } \\
\text { momento }\end{array}$ & 2,6 & Grupo clase & $\begin{array}{l}\text { Registro de las } \\
\text { aportaciones en la } \\
\text { asamblea }\end{array}$ \\
\hline & Act. 15. Ficha individual & 2 & Individual & Ficha individual \\
\hline & $\begin{array}{l}\text { Act. 16. La "L". Búsqueda } \\
\text { de información sobre el } \\
\text { melocotón con las familias }\end{array}$ & $1,3,5,6$ & $\begin{array}{l}\text { Individual-con la } \\
\text { familia/ Grupo } \\
\text { clase }\end{array}$ & Ficha individual \\
\hline & $\begin{array}{l}\text { Act. 17. Exposición de la } \\
\text { información buscada de la } \\
\text { letra "L" y votación de los } \\
\text { mensajes. }\end{array}$ & $1,3,5,6$ & $\begin{array}{l}\text { Individual/Grupo } \\
\text { clase }\end{array}$ & $\begin{array}{l}\text { Observación sistemática } \\
\text { del docente }\end{array}$ \\
\hline & $\begin{array}{l}\text { Act. 18. Grabación de los } \\
\text { audios de los niños }\end{array}$ & $1,3,5,6$ & $\begin{array}{l}\text { Grupo } \\
\text { clase/Individual }\end{array}$ & Audios \\
\hline
\end{tabular}

